\title{
CAPSULE COMMENTARIES \\ Capsule Commentary on Aysola et al., Asking the Patient About Patient-Centered Medical Homes: A Qualitative Analysis
}

\author{
Jeffrey L. Jackson, MD, MPH \\ Division of General Internal Medicine, Zablocki VA Medical Center, Milwaukee, WI, USA.
}

J Gen Intern Med 30(10): 1531

DOI: $10.1007 / \mathrm{s} 11606-015-3397-0$

(c) Society of General Internal Medicine 2015

$\mathrm{T}$ he patient-centered medical home $(\mathrm{PCMH})$ may be the greatest revolution in care delivery that patients have never heard of. The PCMH care model aims to transform the organization and delivery of primary care by putting patients at the center of a care team that provides coordinated, evidence-based care - care that is delivered when, where and how patients want it. ${ }^{1}$ Full adoption of the care process has been stymied by pay systems that reward visits and procedures and may have disincentives for providing population-based care. $^{2}$ However, as Aysola ${ }^{3}$ and colleagues point out, "patients uniformly lack awareness of PCMH concepts even when their care delivery system is a PCMH." Why is this so? Aysola provides a clue: the most important aspect of primary care delivery to patients is their relationship with an individual provider, not a health system. Even when care was delivered through systems that highlighted team-based care, patients saw other members of the team as secondary to the interactions they had with their doctor. The intimacy and immediacy of the relationship between a primary care provider and their patient is not likely to be subsumed by redesigning systems to highlight team-based care. Patients consistently demonstrate loyalty, high satisfaction and trust with their primary are provider. ${ }^{4,5}$ Aysola concludes that practice redesign needs to preserve and build around this relationship.

Conflict of Interest: The author has no conflict of interest with regard to this article.

Corresponding Author: Jeffrey L. Jackson, MD, MPH; Division of General Internal Medicine, Zablocki VA Medical Center, Milwaukee, WI, USA (e-mail: jjackson@mcw.edu).

\section{REFERENCES}

1. Jackson GL, Powers BJ, Chatterjee R, Bettger JP, Kemper AR, Hasselblad V, et al. The patient-centered medical home. A systematic review. Ann Intern Med. 2013;158(3):169-78.

2. Edwards ST, Abrams MK, Baron RJ, Berenson RA, Rich EC, Rosenthal GE, Rosenthal MB, Landon BE. Structuring payment to medical homes after the affordable care act. J Gen Intern Med. 2014;29(10):1410-3.

3. Aysola J, Werner RM, Keddem S, SoRelle R, Shea JA. Asking the patient about patient-centered medical homes: a qualitative analysis. J Gen Intern Med. 2015. doi:10.1007/s11606-015-3312-8.

4. Jackson JL, Chamberlin J, Kroenke K. Predictors of patient satisfaction. Soc Sci Med. 2001;52(4):609-20.

5. Hinchey SA, Jackson JL. A cohort study assessing difficult patient encounters in a walk-in primary care clinic, predictors and outcomes. J Gen Intern Med. 2011;26(6):588-94.

This comment refers to the article available at: http://dx.doi.org/10.1007/ s11606-015-3312-8.

Published online May 16, 2015 